\title{
Postoperative complications and long-term outcomes of tracheoesophageal fistula repair
}

\author{
Anastasia Almog ${ }^{1,2}$, Augusto Zani ${ }^{1,3}$ \\ ${ }^{1}$ Division of General and Thoracic Surgery, The Hospital for Sick Children, Toronto, ON, Canada; ${ }^{2}$ Department of Pediatric and Adolescent \\ Surgery, Schneider Children's Medical Center of Israel, Petach Tikva, Israel; ${ }^{3}$ Department of Surgery, University of Toronto, Toronto, ON, Canada \\ Contributions: (I) Conception and design: Both authors; (II) Administrative support: None; (III) Provision of study materials or patients: None; (IV) \\ Collection and assembly of data: A Almog; (V) Data analysis and interpretation: Both authors; (VI) Manuscript writing: Both authors; (VII) Final \\ approval of manuscript: Both authors. \\ Correspondence to: Augusto Zani, MD, PhD, FACS, FAAP. Division of General and Thoracic Surgery, The Hospital for Sick Children, 655 University \\ Avenue, Room 1524, Roy C. Hill Wing Toronto, ON, M5G 1X8, Canada. Email: augusto.zani@sickkids.ca.
}

\begin{abstract}
Congenital tracheoesophageal fistula (TEF) is part of the esophageal atresia complex and can be associated with multiple congenital anomalies. With advancements in anesthesiology and neonatal intensive care support, the survival rate of infants with TEF has surpassed $90 \%$ and at present, the rare cases of postoperative mortality are typically due to extremely low birth weight and/or to the presence of associated comorbidities, such as congenital heart defects. TEF morbidity is partly secondary to the surgical repair and partly intrinsic to the anatomical anomaly. Postoperative complications include anastomotic leak, stricture, and recurrent fistula. Moreover, some patients develop long-term outcomes that include gastroesophageal reflux (GER) and esophagitis, dysphagia, tracheomalacia, vocal cord disorders, and risk of esophageal malignancy. Many aspects of the management of these short- and long-term sequelae remain controversial and lack a standardized approach. Nonetheless, it is widely accepted that patients with TEF require a multidisciplinary treatment and long-term follow-up. The purpose of this review was to evaluate the recent literature on TEF postoperative complications and long-term outcomes, with focus on the incidence, medical and surgical treatment, and controversial aspect of TEF postoperative management. Understanding the long-term functional outcomes helps to re-evaluate the impact of the old classical approaches of treatment and to optimize the modern medical and surgical techniques and follow-up management.
\end{abstract}

Keywords: Tracheoesophageal fistula (EA/TEF); tracheoesophageal fistula repair; anastomotic leak; anastomotic stricture; recurrent fistula

Received: 17 March 2021; Accepted: 13 July 2021; Published: 25 August 2022.

doi: $10.21037 /$ ccts-21-15

View this article at: https://dx.doi.org/10.21037/ccts-21-15

\section{Introduction}

Tracheoesophageal fistula (TEF) is an abnormal communication in one or more places between the esophagus and the trachea. TEF can present as a congenital anomaly, which is usually associated with esophageal atresia (EA), or as an acquired condition, which is typically iatrogenic or secondary to trauma, malignancy, or infectious processes. Herein, we report the most recent literature on postoperative complications and long-term outcomes of infants with the congenital form of TEF (Table 1).

\section{Postoperative mortality}

With advancements in anesthesiology and neonatal intensive care support, the survival rate of infants with TEF has surpassed $90 \%(1,2)$. Nowadays, the rare cases of postoperative mortality are usually due to extremely low birth weight $(<1,000 \mathrm{~g})$ and/or to the presence of associated comorbidities $(3,4)$. This is in line with a risk classification model proposed by Lewis Spitz in 1994 and based on birth weight and the coexistence of cardiac malformations (5):

* Group 1: Birth weight $>1,500 \mathrm{~g}$ without presence 
Table 1 The most common postoperative and long-term complications in TEF patients

\begin{tabular}{|c|c|}
\hline Postoperative and long-term complications & Incidence (\%) \\
\hline \multicolumn{2}{|l|}{ Postoperative complications } \\
\hline - Anastomotic leak (overall) & $6-8$ \\
\hline - Major leak & 3.5 \\
\hline - Anastomotic stricture (overall) & $10-59$ \\
\hline - Anastomotic stricture in long gap EA & 44 \\
\hline - Associated with trans-anastomotic feeding tube & 56 \\
\hline - Recurrent TEF & $5-10$ \\
\hline - Oral dysphagia & 36 \\
\hline - Pharyngeal dysphagia & 75 \\
\hline - GER & $40-75$ \\
\hline - Eosinophilic esophagitis & 21 \\
\hline - Metaplasia & $21-43$ \\
\hline - Tracheomalacia (overall) & 90 \\
\hline - Tracheomalacia requiring surgical intervention & 10 \\
\hline - Vocal cord dysfunction in H-type EA & 50 \\
\hline
\end{tabular}

TEF, tracheoesophageal fistula; EA, esophageal atresia; GER, gastroesophageal reflux.

of major cardiac anomaly;

* Group 2: Birth weight $<1,500 \mathrm{~g}$ or presence of major cardiac anomaly;

* Group 3: Birth weight $<1,500 \mathrm{~g}$ and presence of major cardiac anomaly.

In 2006, Spitz et al. retested the validity of their classification and reported an increase in survival mainly in group 2 and 3, which they interpreted as due to the improvements in intensive care rather than in surgical techniques (6). More recently, the Midwest Pediatric Surgery Consortium has published the outcomes of their series of infants with EA/TEF and reported that the mortality $(7.5 \%)$ was significantly associated with the presence of congenital heart disease (3).

\section{Postoperative morbidities}

\section{Anastomotic leak}

\section{Definition and presentation}

One of the most common postoperative complications associated with EA/TEF repair is anastomotic leak. Leaks are divided into minor and major according to the degree of anastomotic disruption (7). The distinction can be made based on radiological findings and/or clinical presentation (7-9). Major leaks typically have most of the contrast medium dribbling from the anastomosis into the mediastinum, and present rapid deterioration with lifethreatening pneumothorax or fluid collection. These leaks are likely due to a disruption of $>25 \%$ of the anastomosis. 
Conversely, minor leaks have most of the contrast drained through the distal esophagus, with only a little amount dribbling out of the anastomosis, and patients are usually asymptomatic.

\section{Incidence}

The reported incidence of anastomotic leak ranges from $6 \%$ to $58 \%(3,8,10-14)$, with a higher incidence reported in the group of pure EA. However, it is well established that the leak rate depends on whether an esophagogram is routinely performed postoperatively, as in this case even minor leaks are detected in asymptomatic patients. Similarly, the higher rates reported in patients with pure EA could be attributed to the fact that all these patients routinely receive a postoperative esophagram, so that even clinically insignificant leaks are recorded (10).

\section{Etiology}

Numerous risk factors have been considered in the literature. As leaks are more common in patients with long-gap EA compared to those without long gap, tension between the esophageal leading to blood supply compromise is considered the most significant factor $(3,15)$. Some surgical techniques, such as the two-layer anastomosis and the Livaditis circular myotomy, have also been associated with higher rates of anastomotic leak than other procedures $(8,9,15)$. Evaluation of the suture materials showed that braided silk sutures were associated with a significantly increased risk of anastomotic leak compared with polyglycolic acid or polypropylene sutures (16). Conversely, the approach employed for surgical repair does not seem to affect the leak rate, as shown in a meta-analysis of retrospective comparative studies, where no differences were reported between the thoracoscopic and open approaches (17). Another risk factor described in literature as associated with high incidence of leak rate is the use of postoperative non-invasive ventilation, especially if longer than $48 \mathrm{~h}(18)$.

\section{Management}

To prevent anastomotic leaks, some surgeons opt for postoperative muscle paralysis, endotracheal intubation with mechanical ventilation, and neck flexion (PVF) in patients with an esophageal anastomosis under tension. The PVF protocol, whose duration varies between 2 and 5 days (19), has been shown to reduce the anastomotic leak rate (20). Classically, minor leaks discovered with a routine esophagogram are successfully managed conservatively by parenteral nutrition, broad-spectrum antibiotics, observation, and chest tube drainage if required $(11,13,14,16,21)$. The use of anticholinergic agents has also been described to reduce excessive salivary secretion, control the leak, and promote spontaneous closure of the leak (21). Conversely, major anastomotic leaks should instead be operated on while the anastomotic edge is still fresh for re-suturing before inflammation and necrosis can cause tissue damage. The rationale for the intervention is to prevent serious and potentially fatal complications, such as mediastinitis, mediastinal abscess, sepsis, and tension pneumothorax $(1,11,22)$.

\section{Anastomotic stricture}

\section{Definition and incidence}

Anastomotic stricture is a common morbidity following EA/TEF repair with an incidence ranging between $10 \%$ and $59 \%(3,14,23,24)$. The anastomotic narrowing seen on early postoperative contrast esophagograms is not to be considered as a stricture, rather as postoperative changes due to tissue edema, and it has been proven not to be associated with the development of a stricture in the longterm $(15,25,26)$.

\section{Etiology}

Common risk factors implicated in stricture formation include anastomotic tension, anastomotic leak, and gastroesophageal reflux (GER) (1). Moreover, any vascular compromise during the mobilization of the lower esophagus which has a segmental blood supply from the aorta and the intercostal vessels, may yield to ischemia at the esophageal anastomosis, which may lead to stricture formation (7). Patients with long gap EA undergoing a staged repair have been reported to be at higher risk of stricture formation over those who undergo primary repair $(22,27)$. Nonetheless, the Midwest Pediatric Surgery Consortium reported no differences in stricture rate between patients with and without a long gap EA (3). Several studies have shown that the risk of esophageal stricture is significantly higher in infants that develop an anastomotic leak compared to those without leak, possibly due to local inflammation and scar formation $(11,13,22)$. GER has always been considered a significant predisposing factor for stricture formation $(15,22,28,29)$ and recent evidence shows that a third of EA/TEF patients with clinico-pathological evidence of eosinophilic esophagitis had a history of recurrent stricture (30). Classically anastomotic strictures 
have also been associated with the choice of suture material, with braided silk sutures being considered a significant predisposing factor to stricture formation compared to polyglycolic acid and polypropylene sutures (28). However, a more recent study demonstrated no difference in the incidence of anastomotic stricture between monofilament and braided sutures as well as between absorbable and nonabsorbable sutures (31). The use of magnets to achieve esophageal continuity, also known as magnamosis, has also been reported as a cause of stricture, given the higher need for esophageal dilatations than in patients treated with conventional anastomosis techniques (28). The use of a trans-anastomotic feeding tube has also been suggested as a cause for anastomotic stricture, with a higher stricture rate in patients managed with such a tube compared to those managed without (32). It remains controversial whether anastomotic strictures have similar incidence after open or thoracoscopic TEF repair. One study indicated that the thoracoscopic surgery increased the risk of stricture in $40 \%$ versus $16.3 \%$ stricture rate after open thoracotomy (27). With the development and improvement of thoracoscopic technique recent reviews of the literature and meta-analysis shows no difference in stricture rates in patients between the thoracoscopic and open approaches $(3,17,33)$.

\section{Management}

Anastomotic esophageal strictures are commonly treated with dilatation (26). Bougies were popular in the past and have largely been replaced by balloon dilatations, which can be done under fluoroscopic or endoscopic guidance (26). Timing of the dilatation has also changed over time: in the past, some centers were advocating for esophageal dilations to be performed routinely, in order to prevent the development of a stricture. There is now good evidence showing that postoperative dilatations are necessary only if the patient is symptomatic (34). This approach has been corroborated by a recently published international survey that reported the lack of consensus on the management of anastomotic strictures post-EA/TEF repair and formulated some advisory statements, including performing dilatation procedures in symptomatic patients (35).

In cases of recurrent strictures, esophageal dilatations can be associated with topical application of mitomycin $\mathrm{C}$, intralesional steroids injection, endoscopic treatment with stents or using an endoscopic knife $(25,36,37)$. The use of Mitomycin C, an alkylating agent used in cancer chemotherapy, is based on its anti-fibrotic properties, whereby it inhibits wound healing by downregulating the expression of extracellular matrix proteins, and prevents postoperative scar formation (38-40). Similarly, the use of triamcinolone acetonide, a synthetic corticosteroid with an unclear mechanism of action, is based on its known effects in the treatment of hypertrophic scars of the skin and keloid. However, the success of intralesional triamcinolone acetonide injections has been reported as inconsistent in improving the stricture, and its use accompanied by potential complications including intramural infection, esophageal perforation, mediastinitis, pleural effusion, and adrenal suppression from exogenous systemic steroid administration (41).

Stenting has been reported as an alternative method for refractory esophageal stricture treatment (26,41-43). In the literature, different types of stents have been described based on their mechanisms of action: self-expanding plastic stent; retrievable, fully covered, self-expanding metal stents; and self-expandable, biodegradable stents that allow passage of food inside the stent $(41,42)$. However, stenting has little success in the pediatric population and is often associated with complications and with the disadvantage of the lack of specific sizes for children. A recent systematic review showed that esophageal stents may have a role as a bridge to definitive surgery, rather than achieving complete resolution (44).

When conservative management of recurrent anastomotic strictures fails, surgery in the form of stricturoplasty, stricture resection and reanastomosis, or substitutive interventions (gastric pull-up, colon or jejunal interposition) should be considered (45). The timing of surgery remains controversial. A survey of the International Pediatric Endosurgery Group members reported that some surgeons would opt for surgical intervention after three dilations (46). Conversely, a single-center study of 103 consecutive patients showed that surgery is best predicted if $>10$ dilations are required (47).

\section{Recurrent TEF}

This is a severe complication occurring in approximately $5-10 \%$ of cases, most often between 2 and 18 months following initial repair $(12,13,45,48-51)$.

\section{Etiology}

Recently, Smithers et al. proposed a classification of recurrent TEF based on etiology and anatomy (45): (I) congenital TEF, which persist after TEF repair as they were missed or the repair was incomplete; (II) recurrent TEF that occurs in the same location after primary repair of TEF; 
(III) acquired TEF which occurs in a new location on either the airway side (from the trachea to bronchi to pulmonary parenchyma) or the digestive side (esophageal anastomosis or colon or gastric conduit), or both. In case of a congenital TEF, one should consider the possibility that during the first surgery a rare variant of TEF, such as proximal TEF or double TEF, might have been missed $(22,45,52)$. In case of a recurrent TEF, the surgical approach does not seem to play a role, as no differences have been reported between open and thoracoscopic TEF repair (53). Other causes may include an anastomotic leak, tissue erosion by the sutures or clips applied, trauma secondary to esophageal dilations, and infection $(45,49)$.

\section{Diagnosis}

Diagnostic investigations for recurrent TEF include esophagram, bronchoscopy, esophagoscopy, contrast swallowing, and CT scan. Combining multiple modalities, such as esophagogram, esophagoscopy and bronchoscopy, is recommended by most of the surgeons, as when only one is performed the recurrent TEF is often missed $(45,54,55)$. The diagnosis and localization of recurrent TEF can be difficult due to postoperative of the inflammation. To maximize the chances of localizing the TEF, different maneuvers have been described. These include applying methylene blue into the esophagus under endoscopic guidance (54), introducing a catheter through the fistula from the trachea under bronchoscopy (22), backwards contrasting esophagram (51), CT scan with $3 \mathrm{D}$ reconstruction to have a full anatomic picture of the organo-vascular relationship (45).

\section{Management}

Correction of a recurrent TEF can be challenging and requires experienced skills for a surgeon. Endoscopic techniques have recently been advocated as the primary approach prior to surgical repair. These include stents placement, administration of tissue adhesive substances, combination of electrocautery with tissue glue (cyanoacrylate or fibrin glue) or laser $(54,56)$. For the latter, the authors advocated the use of Bugbee electrocautery at low power on a narrow fistula followed by the application of Tisseel with additional aprotinin to gain better coagulation of the tract (54). However, in some cases, endoscopic attempts are not effective, and can be associated with complications, such as near fatal airway occlusion (45).
Surgery is the classical approach to treat recurrent TEF. According to Coran, it is critical to have the TEF identified and catheterized before opening the chest, the trachea should be completely separated from the esophagus before dividing the fistula, and viable tissue, such as a flap of pericardium or pleura or a lymph node with its blood supply, should be interposed between the suture lines (49). Some surgeons advocate for the rotation of the esophagus away from the trachea in order to separate the suture lines and prevent further recurrence (45).

\section{Long-term morbidities}

\section{Dysphagia}

This is one of the most common symptoms and complaints among children and adult who had EA/TEF repair, with rates as high as $75-100 \%(13,57)$. In a recent study, Coppens et al. showed that the prevalence of dysphagia decreases over time: $55 \%$ in patients $<1$ year of age, $51 \%$ in those $1-4$ years old, $17 \%$ in those $5-11$ years old, and $21 \%$ in those $12-18$ years old (58). Manometry studies have demonstrated weak or absent esophageal peristalsis with impaired or absent contraction pattern (11). Experiments in rats have shown an abnormal intrinsic innervation of the distal esophagus that affects both excitatory and inhibitory intramural nerves (1).

\section{Diagnosis and management}

The video fluoroscopic swallow study is helpful to objectively assess the oral and pharyngeal phases of swallowing, which are affected $36 \%$ and $75 \%$ patients after EA/TEF repair, respectively (58). The severity of dysphagia post-TEF repair can be non-invasively evaluated using the Functional Oral Intake Scale, which includes seven levels ranging from nothing by mouth (level 1) to total oral diet with no restrictions (level 7) $(59,60)$.

Children with TEF/EA and long-term dysphagia often also have structural airway abnormalities such as laryngomalacia, vocal cord paralysis, and tracheomalacia, oropharyngeal abnormalities, laryngeal clefts. Therefore, dysphagia and respiratory dysfunction may present with similar clinical signs, such as choking spells, aspiration, chest discomfort, or food impaction.

Dysphagia is also strongly associated with GER in children with repaired EA, regardless whether they had anti-reflux surgery in the form of fundoplication (58). 


\section{GER and esophagitis}

\section{Definition and etiology}

GER is very common following repair of EA/TEF. It can be defined as reflux of gastric contents causing symptoms such as recurrent regurgitation with or without vomiting, poor weight gain, irritability, heartburn, or coughing (11). GER is caused by congenital dysmotility of the esophagus, incompetence of the lower esophageal sphincter mechanism, possibly due to shortened intra-abdominal esophagus, changes to the angle of His, injury to the vagus nerve during surgery, and widened esophageal hiatus (1,61-64). Anastomotic tension certainly plays a role in the development of GER, as evidenced by the high prevalence of GER in children with long-gap EA (65). A meta-analysis of complications and long-term outcome of children with long-gap EA managed with delayed primary anastomosis, a third of patients required a fundoplication within the first year after surgical repair due to either symptomatic GER (65). Nonetheless, GER can still occur following uncomplicated, tension-free anastomosis where the distal esophagus has remained untouched (1).

The sequelae of GER are substantial and range from recurrent anastomotic strictures to peptic esophagitis, eosinophilic esophagitis, and metaplasia (66). In particular, chronic GER may lead to Barrett's esophagus, a premalignant condition characterized by metaplastic changes of the epithelium of the lower portion of the esophagus. In Barrett's esophagus, the normal stratified squamous epithelium changes to simple columnar epithelium with interspersed goblet cells that are normally present only in the small intestine and large intestine. These histological changes can lead to esophagogastric junctional adenocarcinoma, a devastating malignant tumour with a mortality rate of over $85 \%$. In the last decade, several studies showed that a substantial proportion of patients with repaired EA/TEF developed Barrett's esophagus, predominantly with gastric metaplasia $(67,68)$.

\section{Diagnosis}

The ESPGHAN-NASPGHAN guidelines for the evaluation of GER in children with EA recommend the use of $\mathrm{pH}$-impedance to assess and correlate non-acid GER with symptoms in selected patients, i.e., those symptomatic on antireflux medical therapy (proton pump inhibitors - PPI), those on continuous feeding, those with extradigestive symptoms, and those with a normal $\mathrm{pH}$-probe and endoscopy. In fact, non-acid reflux events are usually missed on $\mathrm{pH}$ monitoring without impedance tracing, a modality that has the additional benefit of correlating extraesophageal symptoms with GER events. Interestingly, many children with repaired EA/TEF that are not on medications may have a normal reflux index yet experience a significant number of non-acid retrograde bolus movements (69).

Another modality that the ESPGHAN-NASPGHAN guidelines consider is the upper gastrointestinal endoscopy with biopsies, which allows to evaluate the status of the esophagus and to rule out the presence of eosinophilic esophagitis (EoE). EoE is a recognized chronic allergic/ immune condition of the esophagus, characterized by an infiltration of eosinophils in the esophageal mucosa. EoE, whose pathogenesis is unclear, has been reported in several patients following EA/TEF repair $(30,70,71)$, with a prevalence that seems $>100$-fold higher than in the general population (72). The ESPGHAN-NASPGHAN guidelines recommend ruling out EoE in patients with GER symptoms and refractory to PPI, before proceeding to antireflux (72). For all of those who instead are asymptomatic, the guidelines recommended routine endoscopy throughout childhood, i.e., after stopping PPI therapy, before the age of 10 years, at transition to adulthood (25).

\section{Treatment}

The management of GER after TEF/EA repair varies widely from conservative anti-reflux medications to several anti-reflux surgical approaches. For medical management, there is no consensus in the literature on the type and the duration of agent of anti-reflux therapy. Surveys of members of the Canadian Association of Pediatric Surgeons and the Midwest Pediatric Surgery Consortium showed that infants with repaired EA/TEF are prophylactically started on anti-reflux medications (PPI and/or H2-receptor antagonists), which are discontinued at different time points up to a year of age $(2,73)$. This approach is reinforced in the ESPGHAN-NASPGHAN guidelines which recommend the prophylactic use of PPI up to the first year of life or longer, in case of persistence of GER symptoms (25). Nonetheless, studies have shown that histological complications, anastomotic stricture and leak rates, and pneumonia were found in patients with repaired EA/TEF regardless of the use of anti-reflux medications $(2,66)$.

The proportion of patients requiring fundoplication widely ranges in various series from $15 \%$ to $100 \%$ (74-77). There are various techniques to perform anti-reflux surgery and they include the Nissen fundoplication, and the partial anterior (Thal, Ashcraft, Boix-Ochoa) and the posterior 
(Toupet) hemi-fundoplication. According to a survey of EA/ TEF on-line communities, which included EA/TEF Family Support Connection and Facebook TEF communities, 73\% of patients underwent a Nissen fundoplication and 14\% had a partial wrap (77).

\section{Tracheomalacia}

\section{Definition and etiology}

Tracheomalacia, which is defined as any degree of tracheal collapse during exhalation, is associated with congenital EA/TEF in almost $90 \%$ of children with EA/TEF $(60,78)$. However, tracheomalacia is clinically significant only in $10 \%$ of patient with EA/TEF (1). When $>70 \%$ of the tracheal wall collapses, usually patients present with symptoms $(60,79)$. Interestingly, the incidence of tracheomalacia in the general population is only $0.05 \%$ (80). The high incidence in EA/TEF patients is partially explained by the fact that both the esophagus and trachea develop from the primitive foregut, and the same developmental stress factor affecting one organ likely affects also the other (81). Moreover, patients with repaired EA/TEF might have a weakness of the tracheal wall due to postoperative changes, prolonged intubation, and esophageal strictures (63).

\section{Diagnosis}

Flexible and rigid laryngotracheobronchoscopy is the method of choice, which is important to perform with spontaneous breathing as tracheomalacia is underestimated in a deeply anesthetized patient (60). To study the airways, a dynamic CT scan performed in two phases, end-inhalation and end-exhalation, can provide useful information about the location and extent of the wall collapse, as well as about the surrounding intra-thoracic structures and vascular anatomy $(45,79)$.

\section{Treatment}

Usually, tracheomalacia improves with age. Nonetheless, symptomatic patients with blue spells, apnea, and recurrent chest infections may require treatment. Medical management consists in optimizing airway clearance using ipratropium bromide or saline nebulizing (79). It is important to remember that administration of betaagonist bronchodilators to infants and children with tracheomalacia may worsen the airflow as it relaxes airway smooth muscle tone $(79,82)$. The classical surgical treatment for tracheomalacia is aortopexy, that is the anchoring of the aorta to the posterior aspect of the sternum, thus drawing the anterior tracheal wall to the front and opening up the airway. More recently, the posterior tracheopexy technique has been described as an alternative, whereby horizontal mattress sutures are passed between the posterior tracheal and mainstem bronchial membrane to the anterior longitudinal spinal ligament under bronchoscopic guidance $(83,84)$.

\section{Vocal cord dysfunction (VCD)}

\section{Etiology}

VCD in patients with repaired EA/TEF is characterized by hoarseness and dysphagia complicated with aspiration (85-88). The rate of postoperative VCD is highest $(50 \%)$ in infants with TEF without EA (H-type) and lowest (4.6\%) in those with EA and a distal TEF $(3,88)$. VCD has also been reported to be more common often in patients with long gap EA (11\%) than in patients with non-long gap EA (6\%) (3). The etiology is typically attributed to an iatrogenic injury to the vagus nerve or to one or both recurrent laryngeal nerves as secondary to intraoperative dissection. This explains the high rates in patients with $\mathrm{H}$-type TEF and long-gap EA that require more extensive dissection of the neck, thoracic inlet, and tracheoesophageal groove, and around the upper pouch $(86,87)$. Similarly, thoracoscopic repair of EA appears to have higher rates of VCD probable due to high dissection of the esophagus into the thoracic inlet (89).

\section{Prevention and treatment}

Preoperative laryngo-trachea-bronchoscopy is highly recommended to investigate the airways and evaluate vocal cord motility at baseline (90). Postoperatively, vocal fold movement is best observed with the patient awake using flexible nasopharyngoscopy $(85,90)$. Intraoperative nerve monitoring with electrodes on the vocal cords has been recommended in order to avoid recurrent laryngeal nerve injury during H-type TEF repair (91). Nonetheless, nerve monitoring does not seem to reduce nerve injury over visual identification of the nerve $(92,93)$.

Most patients after TEF repair with VCD improve spontaneously, although the clinical improvement does not always correlate with vocal cord functional recovery (85). In fact, it has been reported that two-thirds of the children with VCD do not regain vocal cord function $(85,88)$. Otolaryngology consultation and follow-up is recommended in symptomatic patients $(88,90)$. Bilateral VCD may present as life-threatening airway obstruction, requiring tracheostomy or open airway surgery (86). 
Patients with oropharyngeal aspiration may require feeding tube insertion and avoiding of oral feeds. VCD may result in delayed phonation and speech development (90).

\section{Esophageal malignancy}

Esophageal malignancies have been reported in patients with repaired EA/TEF repair, typically in the form of adenocarcinoma or squamous cell carcinoma, but also colorectal carcinoma in patients who underwent colonic interposition $(48,94)$. However, two population-based studies showed that adults with repaired EA/TEF are at no higher risk for malignancy than the general population. One study presenting $>50$-year follow-up for 502 patients reported no cases of esophageal cancer (95), whereas the other described only three patients who had brain cancer, lymphoma and cervical cancer (96).

\section{Conclusions}

Overall, infants and children born with EA/TEF have high survival rates, but they are often affected by a number of postoperative complications. Some of these are intrinsic to the anatomical anomaly and some are secondary to the surgical repair. Many aspects of the management of these short- and long-term sequelae remain controversial and lack a standardized approach. Patients with recurrent strictures, severe dysphagia and GER are still challenging to treat. Long-term multidisciplinary clinic follow-up are common nowadays and help patients to be monitored longitudinally and surgeons to increase their understanding regarding the prevention and treatment of this complex congenital anomaly.

\section{Acknowledgments}

Funding: None.

\section{Footnote}

Provenance and Peer Review: This article was commissioned by the Guest Editor (Tutku Soyer) for the series "Tracheoesophageal Fistula" published in Current Challenges in Thoracic Surgery. The article has undergone external peer review.

Conflicts of Interest: Both authors have completed the ICMJE uniform disclosure form (available at https://ccts. amegroups.com/article/view/10.21037/ccts-21-15/coif). The series "Tracheoesophageal Fistula" was commissioned by the editorial office without any funding or sponsorship. The authors have no other conflicts of interest to declare.

Ethical Statement: The authors are accountable for all aspects of the work in ensuring that questions related to the accuracy or integrity of any part of the work are appropriately investigated and resolved.

Open Access Statement: This is an Open Access article distributed in accordance with the Creative Commons Attribution-NonCommercial-NoDerivs 4.0 International License (CC BY-NC-ND 4.0), which permits the noncommercial replication and distribution of the article with the strict proviso that no changes or edits are made and the original work is properly cited (including links to both the formal publication through the relevant DOI and the license). See: https://creativecommons.org/licenses/by-nc-nd/4.0/.

\section{References}

1. Spitz L. Oesophageal atresia. Orphanet J Rare Dis 2007;2:24.

2. Lal DR, Gadepalli SK, Downard CD, et al. Challenging surgical dogma in the management of proximal esophageal atresia with distal tracheoesophageal fistula: Outcomes from the Midwest Pediatric Surgery Consortium. J Pediatr Surg 2018;53:1267-72.

3. Lal DR, Gadepalli SK, Downard CD, et al. Perioperative management and outcomes of esophageal atresia and tracheoesophageal fistula. J Pediatr Surg 2017;52:1245-51.

4. Zani A, Wolinska J, Cobellis G, et al. Outcome of esophageal atresia/tracheoesophageal fistula in extremely low birth weight neonates ( $<1000$ grams). Pediatr Surg Int 2016;32:83-8.

5. Spitz L, Kiely EM, Morecroft JA, et al. Oesophageal atresia: at-risk groups for the 1990s. J Pediatr Surg 1994;29:723-5.

6. Lopez PJ, Keys C, Pierro A, et al. Oesophageal atresia: improved outcome in high-risk groups? J Pediatr Surg 2006;41:331-4.

7. Morini F, Conforti A, Bagolan P. Perioperative Complications of Esophageal Atresia. Eur J Pediatr Surg 2018;28:133-40.

8. Zhao R, Li K, Shen C, et al. The outcome of conservative treatment for anastomotic leakage after surgical repair of esophageal atresia. J Pediatr Surg 2011;46:2274-8. 
9. Askarpour S, Peyvasteh M, Javaherizadeh H, et al. Evaluation of risk factors affecting anastomotic leakage after repair of esophageal atresia. Arq Bras Cir Dig 2015;28:161-2.

10. Zani A, Cobellis G, Wolinska J, et al. Preservation of native esophagus in infants with pure esophageal atresia has good long-term outcomes despite significant postoperative morbidity. Pediatr Surg Int 2016;32:113-7.

11. Friedmacher F, Kroneis B, Huber-Zeyringer A, et al. Postoperative Complications and Functional Outcome after Esophageal Atresia Repair: Results from Longitudinal Single-Center Follow-Up. J Gastrointest Surg 2017;21:927-35.

12. Dylkowski D, Dave S, Andrew McClure J, et al. Repair of congenital esophageal atresia with tracheoesophageal fistula repair in Ontario over the last 20years: Volume and outcomes. J Pediatr Surg 2018;53:925-8.

13. Kovesi T, Rubin S. Long-term complications of congenital esophageal atresia and/or tracheoesophageal fistula. Chest 2004;126:915-25.

14. Kim W, Son J, Lee S, et al. The learning curve for thoracoscopic repair of esophageal atresia with distal tracheoesophageal fistula: A cumulative sum analysis. J Pediatr Surg 2020;55:2527-30.

15. Yanchar NL, Gordon R, Cooper M, et al. Significance of the clinical course and early upper gastrointestinal studies in predicting complications associated with repair of esophageal atresia. J Pediatr Surg 2001;36:815-22.

16. Chittmittrapap S, Spitz L, Kiely EM, et al. Anastomotic leakage following surgery for esophageal atresia. J Pediatr Surg 1992;27:29-32.

17. Borruto FA, Impellizzeri P, Montalto AS, et al. Thoracoscopy versus thoracotomy for esophageal atresia and tracheoesophageal fistula repair: review of the literature and meta-analysis. Eur J Pediatr Surg 2012;22:415-9.

18. Ferrand A, Roy SK, Faure C, et al. Postoperative noninvasive ventilation and complications in esophageal atresia-tracheoesophageal fistula. J Pediatr Surg 2019;54:945-8.

19. Zani A, Eaton S, Hoellwarth ME, et al. International survey on the management of esophageal atresia. Eur J Pediatr Surg 2014;24:3-8.

20. O'Connell JS, Janssen Lok M, Miyake H, et al. Postoperative paralysis and elective ventilation reduces anastomotic complications in esophageal atresia: a systematic review and meta-analysis. Pediatr Surg Int 2019;35:87-95.
21. Mathur S, Vasudevan SA, Patterson DM, et al. Novel use of glycopyrrolate (Robinul) in the treatment of anastomotic leak after repair of esophageal atresia and tracheoesophageal fistula. J Pediatr Surg 2011;46:e29-32.

22. Koivusalo AI, Pakarinen MP, Lindahl HG, et al. Revisional surgery for recurrent tracheoesophageal fistula and anastomotic complications after repair of esophageal atresia in 258 infants. J Pediatr Surg 2015;50:250-4.

23. Rothenberg SS. Thoracoscopic repair of esophageal atresia and tracheo-esophageal fistula in neonates: evolution of a technique. J Laparoendosc Adv Surg Tech A 2012;22:195-9.

24. Said M, Mekki M, Golli M, et al. Balloon dilatation of anastomotic strictures secondary to surgical repair of oesophageal atresia. Br J Radiol 2003;76:26-31.

25. Krishnan U, Mousa H, Dall'Oglio L, et al. ESPGHANNASPGHAN Guidelines for the Evaluation and Treatment of Gastrointestinal and Nutritional Complications in Children With Esophageal AtresiaTracheoesophageal Fistula. J Pediatr Gastroenterol Nutr 2016;63:550-70.

26. Baird R, Laberge JM, Lévesque D. Anastomotic stricture after esophageal atresia repair: a critical review of recent literature. Eur J Pediatr Surg 2013;23:204-13.

27. Nice T, Tuanama Diaz B, Shroyer M, et al. Risk Factors for Stricture Formation After Esophageal Atresia Repair. J Laparoendosc Adv Surg Tech A 2016;26:393-8.

28. Chittmittrapap S, Spitz L, Kiely EM, et al. Anastomotic stricture following repair of esophageal atresia. J Pediatr Surg 1990;25:508-11.

29. Stenström P, Anderberg M, Börjesson A, et al. Prolonged Use of Proton Pump Inhibitors as Stricture Prophylaxis in Infants with Reconstructed Esophageal Atresia. Eur J Pediatr Surg 2017;27:192-5.

30. Dhaliwal J, Tobias V, Sugo E, et al. Eosinophilic esophagitis in children with esophageal atresia. Dis Esophagus 2014;27:340-7.

31. St. Peter SD, Valusek PA, Snyder CL, et al. Impact of suture choice on stricture formation following repair of esophageal atresia. Ann Pediatr Surg 2007;3:75-9.

32. Fusco JC, Calisto JL, Gaines BA, et al. A large singleinstitution review of tracheoesophageal fistulae with evaluation of the use of transanastomotic feeding tubes. J Pediatr Surg 2017;S0022-3468(17)30648-6.

33. Al Tokhais T, Zamakhshary M, Aldekhayel S, et al. Thoracoscopic repair of tracheoesophageal fistulas: a casecontrol matched study. J Pediatr Surg 2008;43:805-9.

34. Koivusalo A, Turunen P, Rintala RJ, et al. Is routine dilatation after repair of esophageal atresia with distal 
fistula better than dilatation when symptoms arise? Comparison of results of two European pediatric surgical centers. J Pediatr Surg 2004;39:1643-7.

35. Ten Kate CA, Tambucci R, Vlot J, et al. An international survey on anastomotic stricture management after esophageal atresia repair: considerations and advisory statements. Surg Endosc 2021;35:3653-61.

36. Tan Y, Zhang J, Zhou J, et al. Endoscopic Incision for the Treatment of Refractory Esophageal Anastomotic Strictures in Children. J Pediatr Gastroenterol Nutr 2015;61:319-22.

37. El-Asmar KM, Hassan MA, Abdelkader HM, et al. Topical mitomycin $\mathrm{C}$ application is effective in management of localized caustic esophageal stricture: a double-blinded, randomized, placebo-controlled trial. J Pediatr Surg 2013;48:1621-7.

38. Tambucci R, Angelino G, De Angelis P, et al. Anastomotic Strictures after Esophageal Atresia Repair: Incidence, Investigations, and Management, Including Treatment of Refractory and Recurrent Strictures. Front Pediatr 2017;5:120.

39. Gray SD, Tritle N, Li W. The effect of mitomycin on extracellular matrix proteins in a rat wound model. Laryngoscope 2003;113:237-42.

40. Türkyilmaz Z, Sönmez K, Demirtola A, et al. Mitomycin C prevents strictures in caustic esophageal burns in rats. J Surg Res 2005;123:182-7.

41. Lange B, Sold M, Kähler G, et al. Experience with fully covered self-expandable metal stents for anastomotic stricture following esophageal atresia repair. Dis Esophagus 2018. doi: 10.1093/dote/doy061.

42. Caldaro T, Torroni F, De Angelis P, et al. Dynamic esophageal stents. Dis Esophagus 2013;26:388-91.

43. Vandenplas Y, Hauser B, Devreker T, et al. A biodegradable esophageal stent in the treatment of a corrosive esophageal stenosis in a child. J Pediatr Gastroenterol Nutr 2009;49:254-7.

44. Tandon S, Burnand KM, De Coppi P, et al. Self-expanding esophageal stents for the management of benign refractory esophageal strictures in children: A systematic review and review of outcomes at a single center. J Pediatr Surg 2019;54:2479-86.

45. Smithers CJ, Hamilton TE, Manfredi MA, et al. Categorization and repair of recurrent and acquired tracheoesophageal fistulae occurring after esophageal atresia repair. J Pediatr Surg 2017;52:424-30.

46. Lal D, Miyano G, Juang D, et al. Current patterns of practice and technique in the repair of esophageal atresia and tracheoesophageal fistua: an IPEG survey. J Laparoendosc Adv Surg Tech A 2013;23:635-8.

47. Qi BQ, Merei J, Farmer P, et al. Tracheomalacia with esophageal atresia and tracheoesophageal fistula in fetal rats. J Pediatr Surg 1997;32:1575-9.

48. Rintala RJ, Sistonen S, Pakarinen MP. Outcome of esophageal atresia beyond childhood. Semin Pediatr Surg 2009;18:50-6.

49. Coran AG. Diagnosis and surgical management of recurrent tracheoesophageal fistulas. Dis Esophagus 2013;26:380-1.

50. Zimmer J, Eaton S, Murchison LE, et al. State of Play: Eight Decades of Surgery for Esophageal Atresia. Eur J Pediatr Surg 2019;29:39-48.

51. Wang J, Zhang M, Pan W, et al. Management of recurrent tracheoesophageal fistula after esophageal atresia and follow-up. Dis Esophagus 2017;30:1-8.

52. Guo W, Li Y, Jiao A, et al. Tracheoesophageal fistula after primary repair of type $\mathrm{C}$ esophageal atresia in the neonatal period: recurrent or missed second congenital fistula. J Pediatr Surg 2010;45:2351-5.

53. Holcomb GW 3rd. Thoracoscopic surgery for esophageal atresia. Pediatr Surg Int 2017;33:475-81.

54. Richter GT, Ryckman F, Brown RL, et al. Endoscopic management of recurrent tracheoesophageal fistula. J Pediatr Surg 2008;43:238-45.

55. Zhu H, Shen C, Xiao X, et al. Reoperation for anastomotic complications of esophageal atresia and tracheoesophageal fistula. J Pediatr Surg 2015;50:2012-5.

56. Gregory S, Chun RH, Parakininkas D, et al. Endoscopic esophageal and tracheal cauterization for closure of recurrent tracheoesophageal fistula: A case report and review of the literature. Int J Pediatr Otorhinolaryngol 2017;98:158-61.

57. Mahoney L, Rosen R. Feeding Problems and Their Underlying Mechanisms in the Esophageal AtresiaTracheoesophageal Fistula Patient. Front Pediatr 2017;5:127.

58. Coppens CH, van den Engel-Hoek L, Scharbatke H, et al. Dysphagia in children with repaired oesophageal atresia. Eur J Pediatr 2016;175:1209-17.

59. Crary MA, Mann GD, Groher ME. Initial psychometric assessment of a functional oral intake scale for dysphagia in stroke patients. Arch Phys Med Rehabil 2005;86:1516-20.

60. Baxter KJ, Baxter LM, Landry AM, et al. Structural airway abnormalities contribute to dysphagia in children with esophageal atresia and tracheoesophageal fistula. J Pediatr Surg 2018;53:1655-9. 
61. Kawahara H, Kubota A, Hasegawa T, et al. Lack of distal esophageal contractions is a key determinant of gastroesophageal reflux disease after repair of esophageal atresia. J Pediatr Surg 2007;42:2017-21.

62. Tomaselli V, Volpi ML, Dell'Agnola CA, et al. Long-term evaluation of esophageal function in patients treated at birth for esophageal atresia. Pediatr Surg Int 2003;19:40-3.

63. Okata Y, Maeda K, Bitoh Y, et al. Evaluation of the intraoperative risk factors for esophageal anastomotic complications after primary repair of esophageal atresia with tracheoesophageal fistula. Pediatr Surg Int 2016;32:869-73.

64. Zhou B, Hutson JM, Myers NA. Investigation of the intra-abdominal oesophagus and hiatus in fetal rats with oesophageal atresia and tracheo-oesophageal fistula. Pediatr Surg Int 2001;17:97-100.

65. Friedmacher F, Puri P. Delayed primary anastomosis for management of long-gap esophageal atresia: a metaanalysis of complications and long-term outcome. Pediatr Surg Int 2012;28:899-906.

66. Petit LM, Righini-Grunder F, Ezri J, et al. Prevalence and Predictive Factors of Histopathological Complications in Children with Esophageal Atresia. Eur J Pediatr Surg 2019;29:510-5.

67. Schneider A, Gottrand F, Bellaiche M, et al. Prevalence of Barrett Esophagus in Adolescents and Young Adults With Esophageal Atresia. Ann Surg 2016;264:1004-8.

68. Sistonen SJ, Koivusalo A, Nieminen U, et al. Esophageal morbidity and function in adults with repaired esophageal atresia with tracheoesophageal fistula: a population-based long-term follow-up. Ann Surg 2010;251:1167-73.

69. Vergouwe FWT, van Wijk MP, Spaander MCW, et al. Evaluation of Gastroesophageal Reflux in Children Born With Esophageal Atresia Using $\mathrm{pH}$ and Impedance Monitoring. J Pediatr Gastroenterol Nutr 2019;69:515-22.

70. Yamada Y, Nishi A, Kato M, et al. Esophagitis with eosinophil infiltration associated with congenital esophageal atresia and stenosis. Int Arch Allergy Immunol 2013;161 Suppl 2:159-63.

71. Oliveira C, Zamakhshary M, Marcon P, et al. Eosinophilic esophagitis and intermediate esophagitis after tracheoesophageal fistula repair: a case series. J Pediatr Surg 2008;43:810-4.

72. Lardenois E, Michaud L, Schneider A, et al. Prevalence of Eosinophilic Esophagitis in Adolescents With Esophageal Atresia. J Pediatr Gastroenterol Nutr 2019;69:52-6.

73. Shawyer AC, Pemberton J, Flageole H. Post-operative management of esophageal atresia-tracheoesophageal fistula and gastroesophageal reflux: a Canadian Association of Pediatric Surgeons annual meeting survey. J Pediatr Surg 2014;49:716-9.

74. Tovar JA, Fragoso AC. Gastroesophageal reflux after repair of esophageal atresia. Eur J Pediatr Surg 2013;23:175-81.

75. Esposito C, Langer JC, Schaarschmidt K, et al. Laparoscopic antireflux procedures in the management of gastroesophageal reflux following esophageal atresia repair. J Pediatr Gastroenterol Nutr 2005;40:349-51.

76. Bergmeijer JH, Tibboel D, Hazebroek FW. Nissen fundoplication in the management of gastroesophageal reflux occurring after repair of esophageal atresia. J Pediatr Surg 2000;35:573-6.

77. Acher CW, Ostlie DJ, Leys CM, et al. Long-Term Outcomes of Patients with Tracheoesophageal Fistula/Esophageal Atresia: Survey Results from Tracheoesophageal Fistula/Esophageal Atresia Online Communities. Eur J Pediatr Surg 2016;26:476-80.

78. Cartabuke RH, Lopez R, Thota PN. Long-term esophageal and respiratory outcomes in children with esophageal atresia and tracheoesophageal fistula. Gastroenterol Rep (Oxf) 2016;4:310-4.

79. Kamran A, Jennings RW. Tracheomalacia and Tracheobronchomalacia in Pediatrics: An Overview of Evaluation, Medical Management, and Surgical Treatment. Front Pediatr 2019;7:512.

80. Boogaard R, Huijsmans SH, Pijnenburg MW, et al. Tracheomalacia and bronchomalacia in children: incidence and patient characteristics. Chest 2005;128:3391-7.

81. Thyoka M, Barnacle A, Chippington S, et al. Fluoroscopic balloon dilation of esophageal atresia anastomotic strictures in children and young adults: single-center study of 103 consecutive patients from 1999 to 2011. Radiology 2014;271:596-601.

82. Panitch HB, Keklikian EN, Motley RA, et al. Effect of altering smooth muscle tone on maximal expiratory flows in patients with tracheomalacia. Pediatr Pulmonol 1990;9:170-6.

83. Svetanoff WJ, Jennings RW. Updates on Surgical Repair of Tracheobronchomalacia. J Lung Health Dis 2018;2:1723.

84. Shieh HF, Smithers CJ, Hamilton TE, et al. Posterior tracheopexy for severe tracheomalacia. J Pediatr Surg 2017;52:951-5.

85. Fung SW, Lapidus-Krol E, Chiang M, et al. Vocal cord dysfunction following esophageal atresia and tracheoesophageal fistula (EA/TEF) repair. J Pediatr Surg 2019;54:1551-6. 
86. Morini F, Iacobelli BD, Crocoli A, et al. Symptomatic vocal cord paresis/paralysis in infants operated on for esophageal atresia and/or tracheo-esophageal fistula. J Pediatr 2011;158:973-6.

87. Fallon SC, Langer JC, St Peter SD, et al. Congenital H-type tracheoesophageal fistula: A multicenter review of outcomes in a rare disease. J Pediatr Surg 2017;52:1711-4.

88. Zani A, Jamal L, Cobellis G, et al. Long-term outcomes following H-type tracheoesophageal fistula repair in infants. Pediatr Surg Int 2017;33:187-90.

89. Woo S, Lau S, Yoo E, et al. Thoracoscopic versus open repair of tracheoesophageal fistulas and rates of vocal cord paresis. J Pediatr Surg 2015;50:2016-8.

90. Conforti A, Iacusso C, Valfrè L, et al. Cervical repair of congenital tracheoesophageal fistula: Complications lurking! J Pediatr Surg 2016;51:1623-6.

91. Wright TN, Grant C, Hirschl RB, et al. Neural monitoring during $\mathrm{H}$-type tracheoesophageal fistula division: A way to decrease recurrent laryngeal nerve injury? J Pediatr Surg 2019;54:1711-4.

doi: $10.21037 /$ ccts-21-15

Cite this article as: $\mathrm{Almog} \mathrm{A}, \mathrm{Zani} \mathrm{A}$. Postoperative complications and long-term outcomes of tracheoesophageal fistula repair. Curr Chall Thorac Surg 2022;4:30.
92. Lombardi CP, Carnassale G, Damiani G, et al. "The final countdown": Is intraoperative, intermittent neuromonitoring really useful in preventing permanent nerve palsy? Evidence from a meta-analysis. Surgery 2016;160:1693-706.

93. Kadakia S, Mourad M, Badhey A, et al. The role of intraoperative nerve monitoring in tracheal surgery: 20-year experience with 110 cases. Pediatr Surg Int 2017;33:977-80.

94. Vergouwe FW, Gottrand M, Wijnhoven BP, et al. Four cancer cases after esophageal atresia repair: Time to start screening the upper gastrointestinal tract. World J Gastroenterol 2018;24:1056-62.

95. Sistonen SJ, Koivusalo A, Lindahl H, et al. Cancer after repair of esophageal atresia: population-based long-term follow-up. J Pediatr Surg 2008;43:602-5.

96. Oddsberg J, Lu Y, Lagergren J. Aspects of esophageal atresia in a population-based setting: incidence, mortality, and cancer risk. Pediatr Surg Int 2012;28:249-57. 